\title{
Analysis of Factors Influencing Particulate Matter Emissions of a Compression-Ignition Direct-Injection Engine
}

\author{
Laurentius W. Jaeger, Konstantinos Boulouchos \\ ETH Zürich
}

Martin Mohr

EMPA Dübendorf

Copyright (c) 1998 Society of Automotive Engineers, Inc.

\section{ABSTRACT}

The relative amounts of heat released by premixed and by diffusion controlled combustion is varied in a compression-ignition engine run on the test bench through variation of four operating parameters. Exhaust gas is led to a differential mobility particle sizer and to filters that are loaded for gravimetric analysis. Particle size distributions are acquired in the $16 \div 630 \mathrm{~nm}$ range of electrical mobility diameters. Opacity readings of the exhaust gas are taken, cylinder pressure is indicated, a value for the combustion noise is computed; gaseous emissions are recorded and heat release rates based on cylinder pressure analysis are evaluated.

Two full factorial experiments at 2 bar bmep 2000 rpm are run as 24 combinations of four factors: Injection pressure 400 and 1200 bar, with and without pilot injection, $1 / 3$ and $1 / 4$ mass-fraction exhaust gas recirculation, late, middle and early start of injection.

Number, mass and averaged size of the detected particles decrease, when the relative importance of premixed combustion is increased. Limited oxygen availability acts in the opposite direction. The reduction in mean electrical mobility diameters is associated with the reduction in particle numbers. Only with very early heat release, a significant reduction in averaged size is seen, without decrease in the number of detected particles

\section{INTRODUCTION}

\section{Motivation}

Particulate matter emissions of engines are generally characterized by specific weight ( $\mathrm{g} / \mathrm{kWh}$, or $\mathrm{g} / \mathrm{km})$. Optical methods, as measurements of opacity, or defined smoke numbers are also in use. In recent years devices capable of measuring size number distributions of aerosols even in the nanometer range have become commercially available. Concern with possible health hazards associated with particles in the nanometer range has come up. Besides the optimization of current engines to reduce particulate matter emissions, further improvements are sought. Efficient filtering of the exhaust gas is under development. Homogeneous charge engines with compression ignition are investigated. To clarify if this new type of engine could aid to substantially reduce emissions of particles this work has been undertaken.

\section{Hypothesis}

We assume that variations in the relative amounts of premixed and diffusion controlled combustion are one primary cause, influencing the number of emitted particles, in small $\mathrm{Cl}$ engines operated at part load. Oxygen availability and temperature history of the burnt fuel-air mixture are expected to influence the measured size distributions.

\section{Objective}

A set of experimental data is acquired, processed and presented for the discussion of the hypothesis, and the conclusions that follow, for the conception of cleaner new engines.

\section{Procedure}

A modern compression-ignition direct-injection mass produced 4-cylinder engine with 2 liter displacement has been equipped with a common-rail system. It is run on the test bench and serves as a tool for the present work, in order to investigate and possibly verify the hypothesis. With constant speed and load (2000 rpm, 2 bar bmep), the engine is operated with 24 different combinations of the four parameters listed in Table 1 and 2, so that the length of the ignition delay as well as the rates of fuel 
evaporation and mixing are influenced. Exhaust Gas is sampled after the turbine. Particle size distributions are registered and discussed together with the results of heat release analysis.

\section{EXPERIMENTAL SETUP}

Exhaust gas for the Scanning Mobility Particle Sizer SMPS is retrieved from the exhaust pipe, with a probe 0.5 meter after turbine, before catalytic converter. Figure 1. The insulated exhaust pipe with $55 \mathrm{~mm}$ diameter is straight, oriented downwards, from soon after the turbine to $0.2 \mathrm{~m}$ after the probe location. The samples for opacity measurements are taken from the tailpipe.

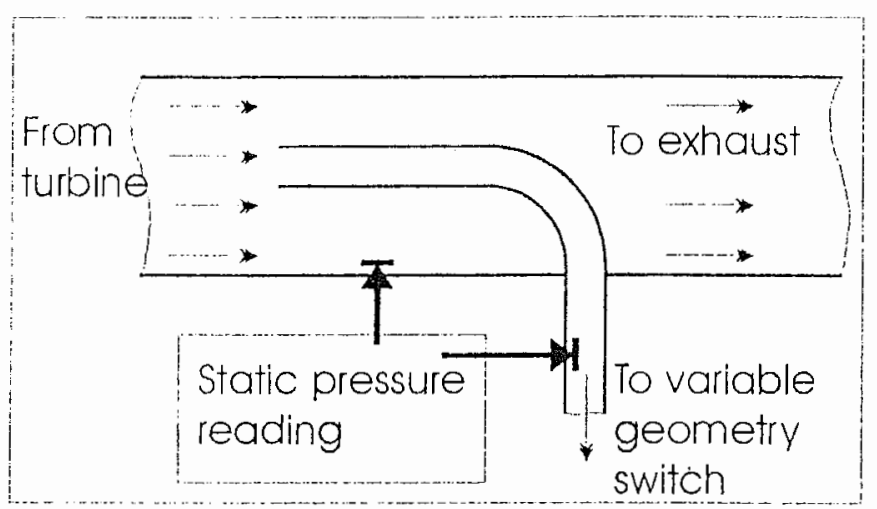

Figure 1: Gas sampling from exhaust pipe. The probe and the exhaust pipe have 12 and $55 \mathrm{~mm}$ inner diameter.

\section{Exhaust Gas Sampling}

The air mass flow through the engine operated at constant speed and load varies with changing EGR rates and turbocharger operating points. The analyzers draw a constant quantity of exhaust gas. As a consequence the acceleration of the sampled gas, at the entrance to the probe, might change in magnitude and sign, from one measurement to another Figure 1. To avoid this, equal kinetic sampling conditions in the exhaust pipe have been realized for all measurements, by varying the amount of gas retrieved by the probe. Figure 2 . The opening of a blow-off valve between the probe and the analyzers is steered to different positions in order to keep the time average of the static pressure in the probe equal to the one in the exhaust pipe. The bifurcation to the blow off valve has a variable geometry, to allow isokinetic branching off.

\section{Conditions in the Sample Lines}

An expansion box is mounted into the flow path, in order to dampen pressure fluctuations, that would be detrimental to the function of the dilution units. Amplitudes, before the dilution units, are kept smaller than 20 mbar. Residence time in the air box is $<4 \mathrm{~s}$. The air box as well as all the lines between probe and dilution units are insulated and heated to $220^{\circ} \mathrm{C}$, on their outer surface. Gas temperatures before dilution units are $>180^{\circ} \mathrm{C}$.

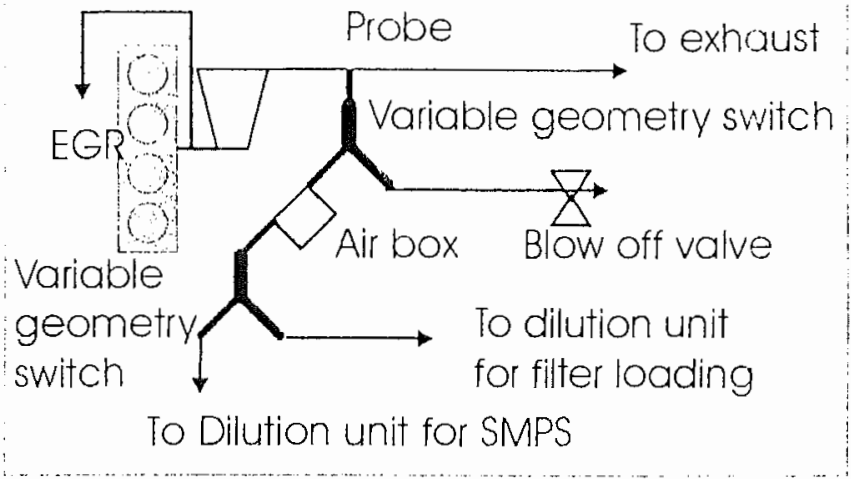

Figure 2: Flow path between exhaust pipe and analyzers.

\section{Dilution Units}

A partial flow dilution tunnel (mini tunnel) is placed between the air box and the Smart Sampler. Temperatures: Dilution air $90^{\circ} \mathrm{C}$, at tunnel entrance 63$74{ }^{\circ} \mathrm{C}$, filter $47-49^{\circ} \mathrm{C}$. Raw gas flow rate is $7.1 \mathrm{l} / \mathrm{min}$, dilution ratio 13.3 .

A rotating disk dilution unit is placed between the air box and the SMPS analyzer. It's dilution method allows a very fast and well defined dilution. The dilution system ensures a dilution of the exhaust gas by a factor 133 in a single step. The principle of the dilution unit is based on a pulsed injection technique. Small cavities are filled with an aerosol portion which is transported from the undiluted aerosol stream (raw gas channel) into a second channel with a particle free gas stream (dilution gas channel). The shuffling between the two channels is done by a disk containing 10 cavities and rotating with an adjustable frequency. The dilution ratio is determined by the volume of the cavities, the shuffling frequency and the flow rate in the dilution gas channel. The body of the unit is heated with heating resistance to about $90^{\circ} \mathrm{C}$.

\section{Scanning Mobility Particle Sizer}

A ionisation source is used to impart a defined charge distribution to the suspended particles. The particles are then exposed to an electrical field under laminar flow conditions. They are thereby deflected from the general direction of gas flow to various degrees depending on their charge and size. A narrowly defined mobility class of the particles is separated out through a narrow slit in the inner electrode by applying a corresponding electrical voltage. Particles collected in this manner are then enlarged by means of condensation in a supersaturated alcohol vapor chamber and then counted optically by means of incident light pulses.

The SMPS is used in the size range of 16 to $630 \mathrm{~nm}$, that is divided in 52 classes. 


\section{FACTORIAL DESIGN OF THE EXPERIMENTS}

\section{OBJECTIVES OF THE MEASUREMENTS}

In small high-speed compression-ignition engines for automotive applications the combustion takes place only in part as diffusion controlled process. A part of the total heat is released by a premixed-type, very fast reaction from that part of the injected fuel, that is evaporated and has mixed with oxygen during the ignition delay.

With constant engine speed and load, selected parameters are varied, so that two main effects are obtained.

1. The length of the ignition delay as well as the rates of evaporation and mixing are influenced. With different combinations of the parameters the fractions of the fuel participating in the premixed combustion are varied between $2 / 5$ and $3 / 5$.

2. The emissions of particulate matter are varied.

A correlation between these effects is searched.

\section{TEST ENGINE}

The engine is a state-of-the-art passenger car engine that has been equipped with an experimental injection system: Injection pressure, its timing, the parameters of multiple injection, as well as EGR rate can be varied, independently, between the extremes of their ranges.

It is run at $2000 \mathrm{rpm}$ and 2 bar bmep. Extreme parameter combinations can be run safely at this regime. Low sulfur fuel ( $<50$ ppm $S$ ) is employed, in an effort to minimize the output of non carbon particles.

\section{DESIGNATIONS IN THE EXPERIMENTS}

\begin{tabular}{|l|l|l|l|l|}
\hline FACTORS & $\begin{array}{l}\text { Symbol } \\
\text { when } \\
\text { not set }\end{array}$ & $\begin{array}{l}\text { Value } \\
\text { when } \\
\text { not set }\end{array}$ & $\begin{array}{l}\text { Symbol } \\
\text { when } \\
\text { set }\end{array}$ & $\begin{array}{l}\text { Value } \\
\text { when } \\
\text { set }\end{array}$ \\
\hline $\begin{array}{l}\text { Rail } \\
\text { Pressure }\end{array}$ & $\mathrm{O}$ & $40 \mathrm{MPa}$ & $\mathrm{A}$ & $120 \mathrm{MPa}$ \\
\hline $\begin{array}{l}\text { Pilot } \\
\text { Injection }\end{array}$ & $\mathrm{O}$ & Yes & $\mathrm{B}$ & No \\
\hline EGR & $\mathrm{O}$ & $\lambda=2.1$ & $\mathrm{C}$ & $\lambda=2.5$ \\
\hline SOI & $\mathrm{O}$ & $+6{ }^{\circ} \mathrm{CA}$ & $\mathrm{M}$ & Middle \\
\hline
\end{tabular}

Table 1: Parameters varied in the first full factorial experiment designated with 'Experiment SOI LateMiddle'. Engine operating modes corresponding to all 16 combinations of factors are tested: $0000, \mathrm{AOOO}$, OBOO, ABOO ...ABCM.

A $2^{4}$ full factorial experiment consists of 16 single experiments. Four factors are varied each one on two levels, set and not-set. The effects of interest are measured with the engine running in all 16 possible combinations of the factors (parameters) settings. The 16 single experiments are designated with a letter code. The first letter always refers to the state of the factor 'Injection Pressure'. The second one refers to the state of the factor 'Pilot Injection'. The third one refers to the factor 'EGR Rate' and the fourth one refers to the state of the factor 'start of injection'(SOI)

\begin{tabular}{|l|l|l|l|l|}
\hline FACTOR & $\begin{array}{l}\text { Symbol } \\
\text { when } \\
\text { not set }\end{array}$ & $\begin{array}{l}\text { Value } \\
\text { when } \\
\text { not set }\end{array}$ & $\begin{array}{l}\text { Symbol } \\
\text { when } \\
\text { set }\end{array}$ & $\begin{array}{l}\text { Value } \\
\text { when } \\
\text { set }\end{array}$ \\
\hline $\begin{array}{l}\text { Injection } \\
\text { Pressure }\end{array}$ & $\mathrm{O}$ & $40 \mathrm{MPa}$ & $\mathrm{A}$ & $120 \mathrm{MPa}$ \\
\hline $\begin{array}{l}\text { Pilot } \\
\text { Injection }\end{array}$ & $\mathrm{O}$ & Yes & $\mathrm{B}$ & No \\
\hline EGR & $\mathrm{O}$ & $\lambda=2.1$ & $\mathrm{C}$ & $\lambda=2.5$ \\
\hline SOI & $\mathrm{M}$ & Middle & $\mathrm{D}$ & $-6^{\circ} \mathrm{CA}$ \\
\hline
\end{tabular}

Table 2: 'Experiment SOI Middle-Early': Only 8 additional engine operating modes needed to be driven in order to perform a second full factorial experiment The 8 combinations containing ' $M$ ' as a factor, are shared by the two experiments. They represent the low setting of the parameter SOI in one experiment, and the high state in the other one.

- Rail pressure is named in the following injection pressure.

- Realization of pilot injection is arbitrary, the shortest possible pilot electric pulse lengths are chosen. They are a function of rail pressure: $6{ }^{\circ} \mathrm{CA}$ with $120 \mathrm{Mpa}$ and $7{ }^{\circ} \mathrm{CA}$ at $40 \mathrm{Mpa}$. The dwell between the two electric pulses is $8^{\circ} \mathrm{CA}$. The start of injection is kept constant for the main injection, identical with and without pilot injection.

- Exhaust Gas Recirculation is the controlled variable in a closed loop with the signal from a wide-range lambda sensor as control variable. $\lambda=2.1$ corresponds to EGR values around $33 \% ; \lambda=2.5$ corresponds to EGR values around $25 \%$. The correlation depends on the variable efficiencies of scavenging, of the turbocharger and of the engine.

- Start of injection SOI is defined relative to a middle value close to maximum brake torque timing.

The designation of the factor levels is chosen so, because the PM emissions of $\mathrm{Cl}$ engines are generally expected to be low with each of the four factors set. Experiment $A B C D$, with high injection pressure $(A)$, no pilot injection (B), low EGR rate (C) and early start of injection (D) is supposed to yield the lowest PM emissions. On the other hand the experiment 0000 , is expected to yield the highest PM emissions, with low injection pressure, pilot injection, high EGR rate (low $\lambda$ ) and late start of injection. For the parameter SOI this consideration applies only, if the effect of the oxidation of soot, that is generated early in the expansion stroke, is regarded as the mechanism that defines the amount of emitted PM. 
Summarizing equations are derived from the experimental data for the effects of interest, e.g. mean size of particles, exhaust opacity, portion of premixed heat release etc. In this work summarizing equations are written as

\section{Effect $=m+A+B+A B+C+. .+A B C D$ [Unit of theEffect]}

where: $m$ is the average effect of the 16 measurements

$A$ is the increase in effect caused by factor $A$

$B$ is the increase in effect caused by factor $B$

$A B$ is the increase in effect caused by the interaction of the factors $A$ and $B$, and so on

These cuefficients are presented as bar diagrams.

\section{DEFINI IIONS OF PARTICULAR TERMS}

Please iefer to the last page for the legend with the symbols that are used in the diagrams.

Premixed Combustion Portion (PCP): 1-zone heat release analysis of the cylinder pressure signal is performed with 'WEG' software [1]. A comparative value is defined for that portion of the integrated heat release, that is regarded as being the result of premixed combustion. (Premixed Combustion Portion PCP). The PCP value is an estimate for the percentage of the total heat release that is generated by the premixed combustion in the course of one-averaged-cycle. It is used in this work for comparisons between different engine operating modes. Figure 3 . The ${ }^{\circ} \mathrm{CA}$ where the second derivative of the heat release rate $\mathrm{dQ} / \mathrm{d} \phi$ becomes negative, in an interval around the end of the highest heat release rate, defines point $z$. The value of the integrated heat release (IHR) in point $z$ is designated as PCP.

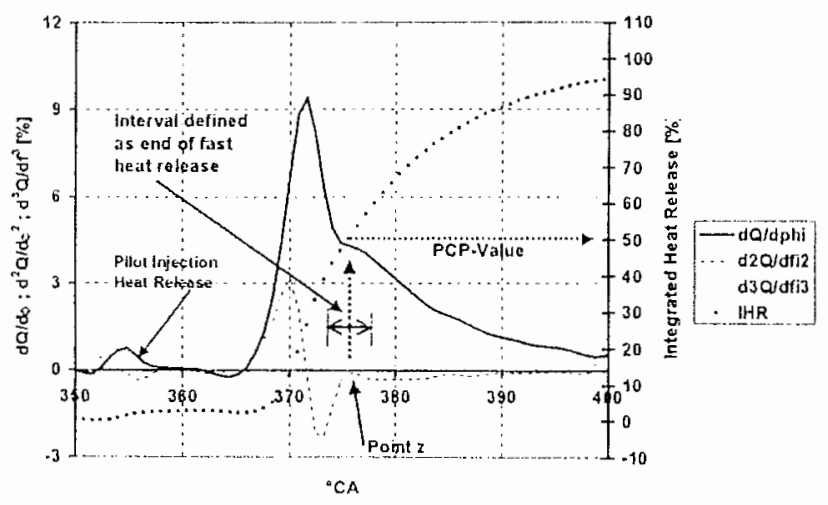

Figure 3: Definition of the comparative value of premixed integrated heat release PCP.

In this work PCP values have been obtained in the range of 43 to $67 \%$ of the total heat release.

Combustion noise values are derived from cylinder pressure monitoring by a 'AVL 450 Noise Meter'. High noise levels are typical for premixed combustion [2]. Correlation is observed in Figure 4 between calculated combustion noise signals, and PCP. The extent of the 4 agreement depends on start of injection. Variations of EGR rate, have negligible effect on combustion noise and PCP.

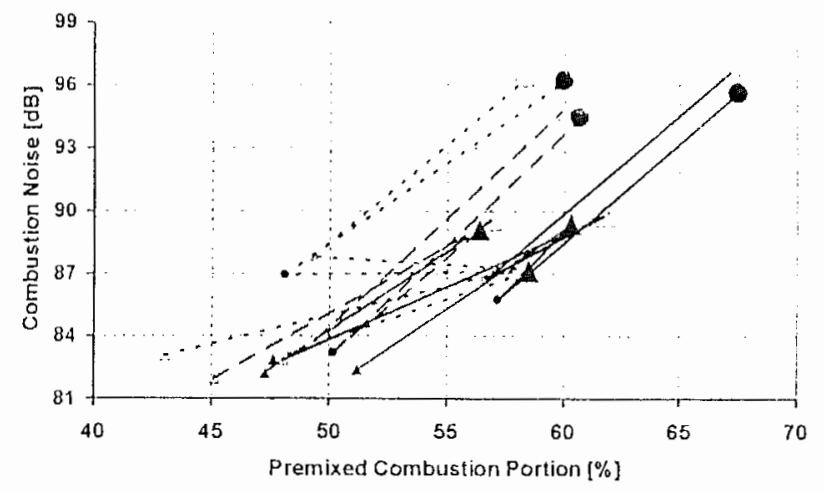

Figure 4: Correlation between calculated combustion noise and premixed combustion portion (PCP).

Particle Size Distributions: Particles ranging from 16 to $630 \mathrm{~nm}$ electric mobility diameter are scanned. Size distributions are plotted with logarithmic axis, and constant scale.

Particles with electrical mobility diameter $<50 \mathrm{~nm}$ are referred to as nanoparticles. The remainder of the detected particles are larger and are referred to as fine particles [3]. Coarse particles with diameter $>630 \mathrm{~nm}$ are not detected with the particle counter. They are registered nevertheless as load on filters and as engine exhaust opacity.

Number of Detected Particles: The particles in the scanned size range are counted, that are detected in $1 \mathrm{~cm}^{3}$ of exhaust gas at normal condition. For a range of Diesel engines and operating conditions, number concentrations between $10^{7}$ and $10^{9}$ particles per $\mathrm{cm}^{3}$ are reported in the literature, whereas the value for spark ignition engines are expected between $10^{5}$ and $10^{6}$ [3].

Volume of Detected Particles: The value is calculated under the assumptions that the particles are spheres with diameters equal to the classes of electrical mobility diameters, and integrated over the scanned size range.

Number of Particles per Volume Particulate Matter NPVP: The quotient of the number and the volume of the detected particles is calculated [3], and is here referred to as NPVP. It is an indicator for the graininess of the detected particles. A high value indicates a high proportion of fine particles, a low value a high proportion of coarse particles. NPVP values depend on the size range that is scanned. SMPS number data indicate that gasoline engines emit a lower proportion of large particles [6]. Higher NPVP values are expected with increasing PCP values.

Particulate Matter Mass: The mass of the particulate matter collected on filters is referred to as PM mass. No limitation by the scanned size range applies to this term.

Constituents of the detected particles: It has to be noted that no statements are made in this work about the composition of the detected particles. Uncertainty exists in this context especially with respect to the nanoparticles, that might contain a large soluble fraction. 


\section{RESULTS}

\section{RELATION BETWEEN THE FACTORS AND THE COMBUSTION REGIMES}

The thermodynamic state of the charge during evaporation and mixing of the injected main fuel quantity is varied in the performed experiments, with the parameters start of injection and pilot injection (Figures 5-7). At the beginning of the main combustion the pressure in the cylinder ranges between 4 and $6 \mathrm{Mpa}$. The time that is thus assigned to the injected fuel to evaporate and mix with fresh air is varied.

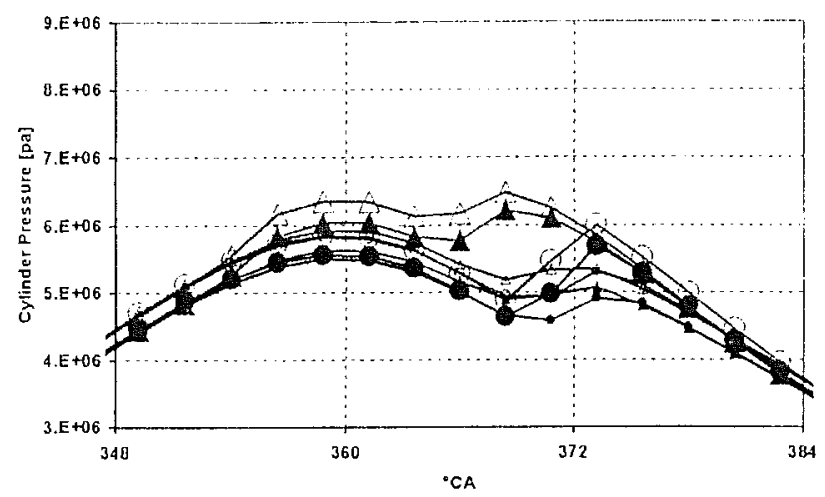

Figure 5: Measured cylinder pressure in the eight single experiments with late start of injection.

More fuel is injected during a given ignition delay with higher injection pressure. The quantity of the injected fuel, that has enough time to be prepared for a premixed combustion increases with increasing injection pressure.

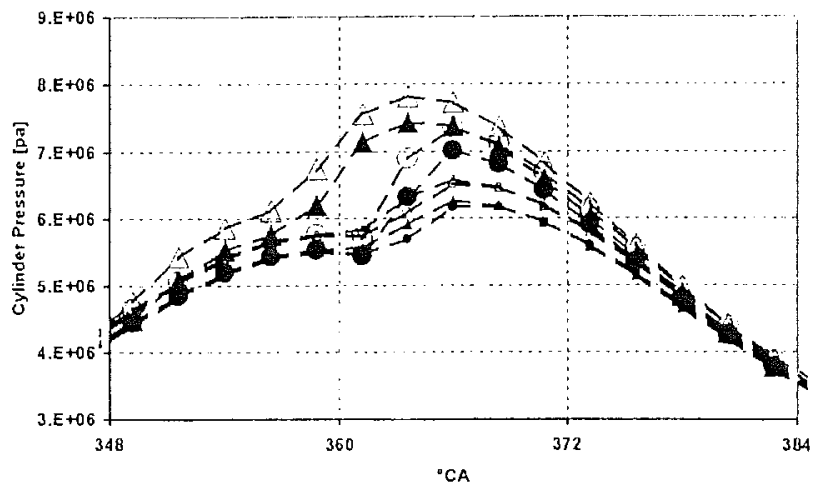

Figure 6: Measured cylinder pressure in the eight single experiments with middle start of injection.

Variations in EGR rate have little effect on PCP, combustion noise (Figure 4) and rates of heat release (Figures 16-18). Nevertheless high EGR rates lead to significantly more fine particles ( $>50 \mathrm{~nm}$ ) and slightly less nanoparticles $(<50 \mathrm{~nm})$, with late and middle SOI. By reducing the oxygen availability they influence directly the emissions of particles as shown by opacity measurements, the results of gravimetric analysis and size distributions (Figures 13-15). No significant correlation is observed between the factor EGR rate and the distribution between the two combustion modes, for the selected engine speed and load conditions.

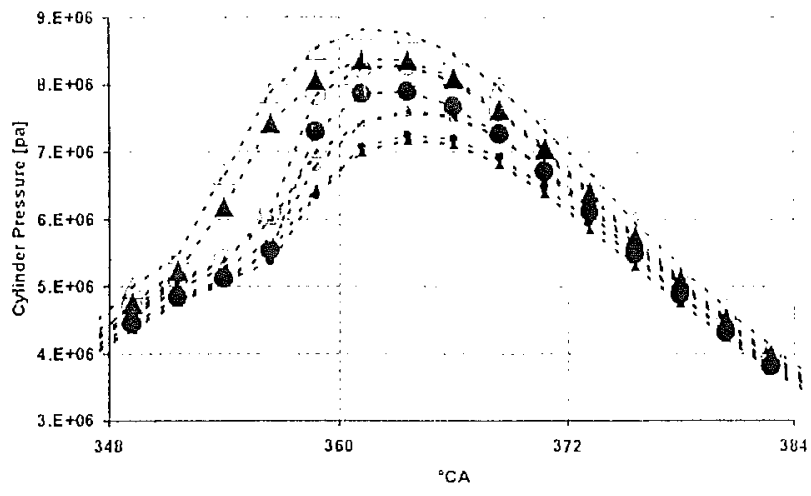

Figure 7: Measured cylinder pressure in the eight single experiments with early start of injection.

\section{RELATION BETWEEN NUMBER SIZE DISTRIBUTIONS AND HEAT RELEASE RATES}

\section{Four selected experiments}

Cases of identical size distributions are registered with different parameter sets (Figure 8). Start of injection and EGR rate is the same for the four sets. From the experiment with the smallest PCP value to the one with the largest PCP value a significant decrease in the number of fine particles $(>50 \mathrm{~nm}$ ) is observed, together with a weak increase in the number of nanoparticles (smaller than $50 \mathrm{~nm}$ ). Two of these experiments (AOOO and $\mathrm{OBOO}$ ) yield an almost identical size distribution although injection pressure is different, 120 and $40 \mathrm{Mpa}$ respectively. The higher pressure is driven with $\mathrm{PI}$, the lower without. The PCP values of experiments AOOO and $\mathrm{OBOO}$ are quite similar (60 and $57 \%$ ).

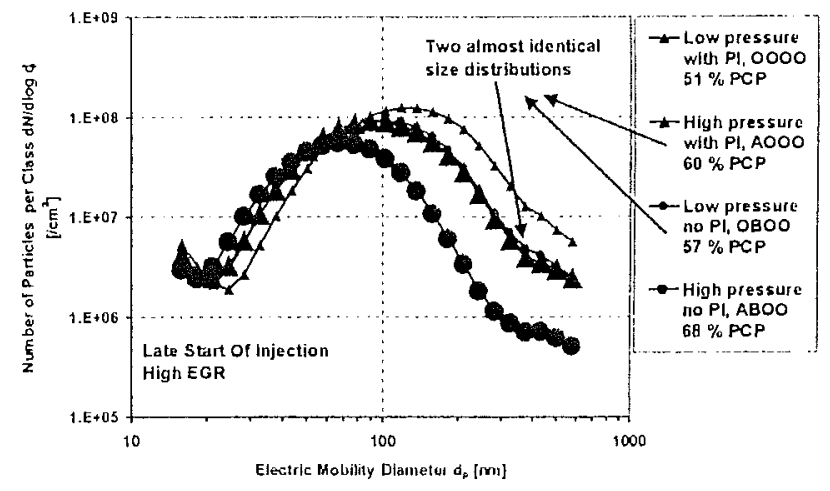

Figure 8:. Particle size distributions of four experiments with late start of injection and high EGR $(\lambda=2.1)$. Variation of rail pressure with and without pilot injection. Large symbols: High rail pressure. Small symbols: Low rail pressure.

The four heat release rates corresponding to Figure 8 are shown in Figures 9-12. In Figure 9 the end of the fast portion of heat release is near $375^{\circ} \mathrm{CA}$. At that time about $45 \%$ of the chemical energy is converted to heat. In Figure 10 the end of the fast portion of heat release is well before $375{ }^{\circ} \mathrm{CA}$. At $375{ }^{\circ} \mathrm{CA}$ about $75 \%$ of the chemical energy is converted to heat. In Figure 11 the end of the fast portion of heat release is near $375^{\circ} \mathrm{CA}$. At that time about $50 \%$ of the chemical energy is 
converted to heat. In Figure 12 the end of the fast portion of heat release is near $375{ }^{\circ} \mathrm{CA}$. At that time about $65 \%$ of the chemical energy is converted to heat. No connection is seen between the timing of the heat release and the similarities (or differences) of the size distributions. A particularity of the pilot injection with high rail pressure of set $A 000$ (Figure 10) is to be noted: The combustion of the pilot spray contributes with an important part to the computed premixed combustion portion.

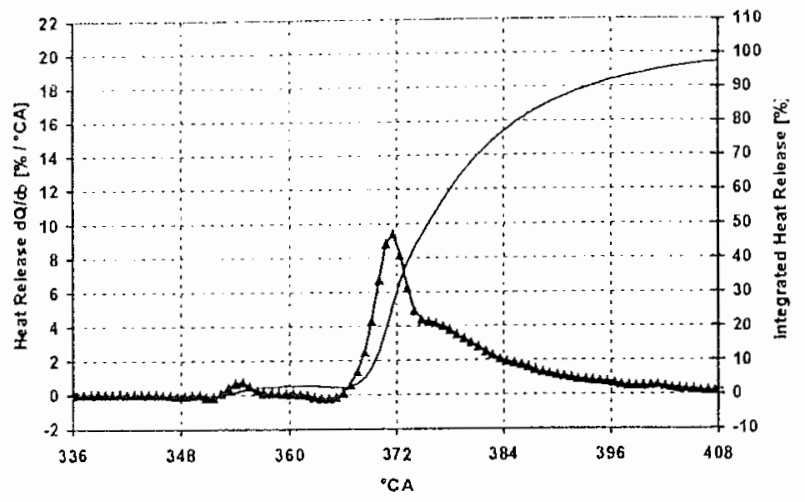

Figure 9: Low rail pressure with pilot injection, high $E G R$ and late $\mathrm{SOI}(\mathrm{OOOO})$. Heat release rate $d Q / d \phi(H R R)$ and integrated heat release (IHR).

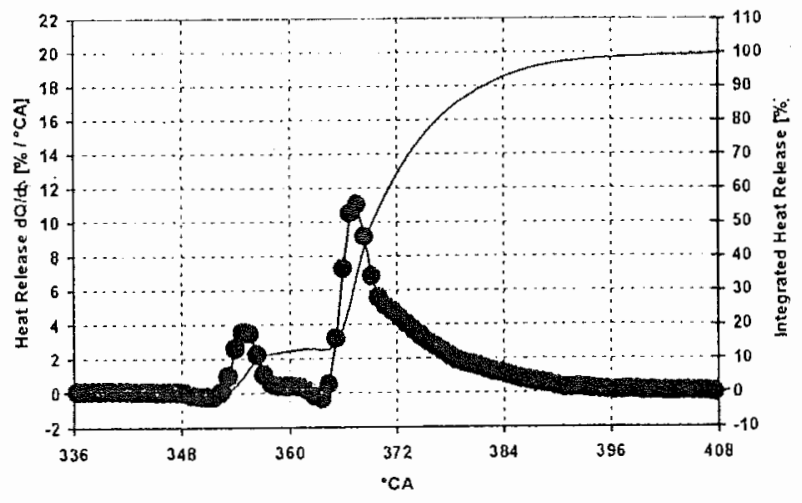

Figure 10: High rail pressure with pilot injection, high EGR and late $\mathrm{SOI}(\mathrm{AOOO})$. Heat release rate $\mathrm{dQ} / \mathrm{d} \phi$ (HRR) and integrated heat release (IHR)

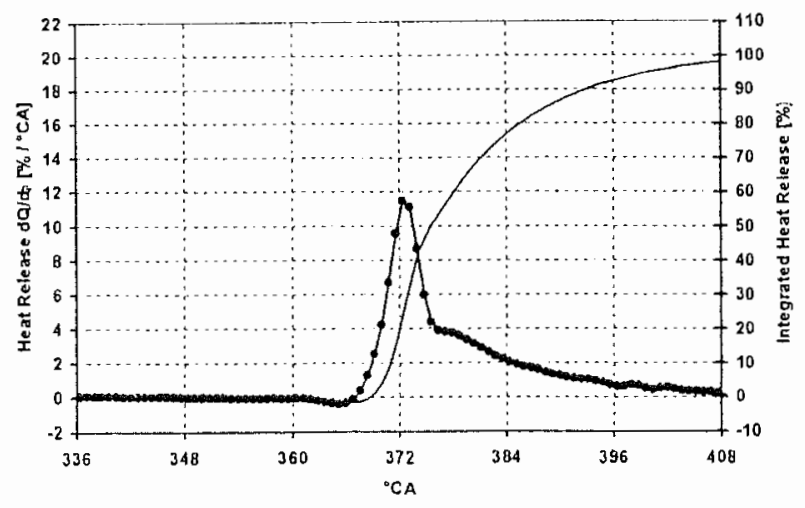

Figure 11: Low rail pressure without pilot injection, high EGR and late SOl (OBOO). Heat release rate dQ/ d $\phi$ (HRR) and integrated heat release (IHR).

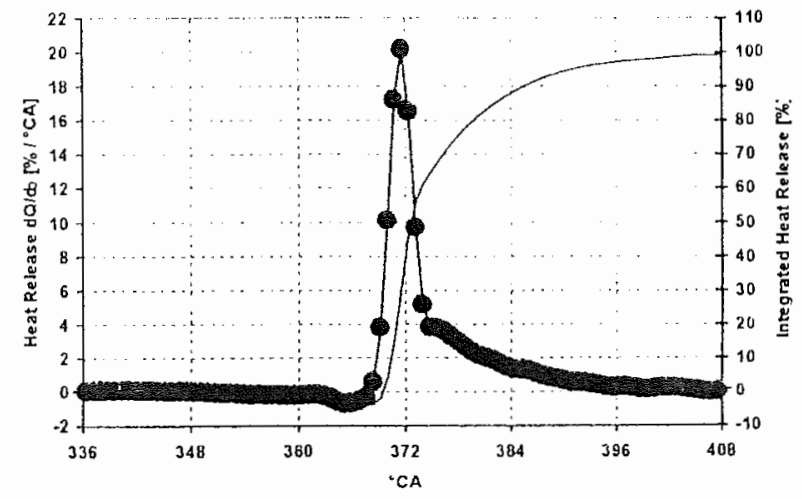

Figure 12: High rail pressure without pilot injection, high $E G R$ and late $S O I$ (ABOO). Heat release rate $d Q / d \phi$ (HRR) and integrated heat release (IHR).

Partticle size distributions and results of heat release analysis for the 24 tested engine operating conditions, grouped by SOI

With late start of injection the setting of any parameter has a significant effect on the particle size distribution, however different combinations of parameters may show identical effects. The experiments AOOO, OBOO and OOCO result in identical size distributions, all three being significantly different then the one produced with experiment 0000 . In Figure 13 reductions in the number of fine particles are associated with weak increases in number of nanoparticles. The curves with PI and high rail pressure have more fine particles $(>50 \mathrm{~nm})$ and less nanoparticles $(<50 \mathrm{~nm}$ ) than the corresponding curves without $\mathrm{Pl}$. The curves with $\mathrm{Pl}$ and low rail pressure have more fine particles (>50nm) and less nanoparticles $(<50 \mathrm{~nm})$ than the corresponding curves without PI. Pilot injection has visible effects -with late SOI-, both with high and low injection pressure.

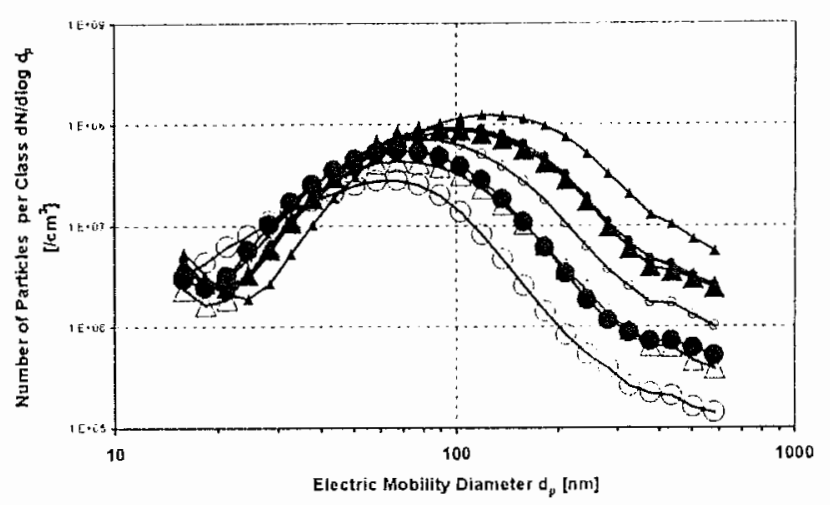

Figure 13: The eight size distributions measured with late start of injection.

From this and the following two pictures it can be seen that he number of the largest particles that are detected in this work varies by almost two orders of magnitude whereas the number of the smallest nanoparticles $\quad<50$ $\mathrm{nm}$ ) vary by only one order of magnitude. These two variations occur in the opposite direction. 
In Figure 14 note the curves with high and low rail pressure: A difference between the ones with and the ones without pilot injection is observed only with high EGR and high rail pressure. Pilot injection has little effects on these size distributions with middle SOI.

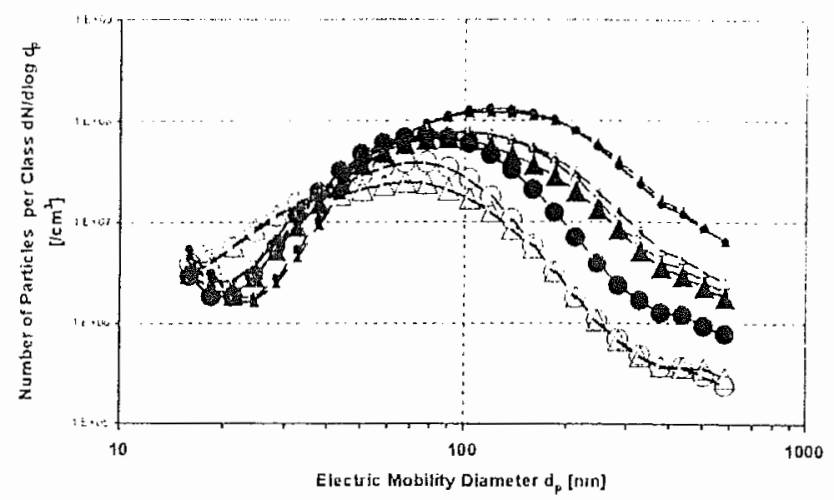

Figure 14: The eight size distributions measured with middle start of injection.

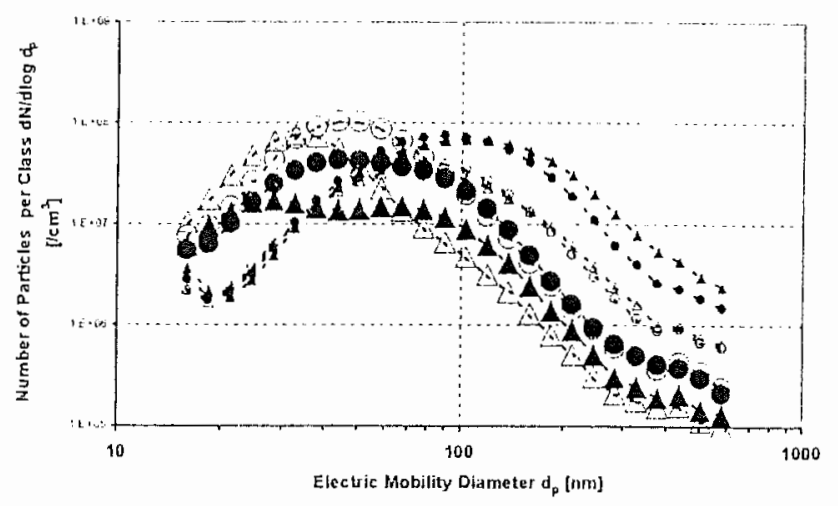

Figure 15: The eight size distributions measured with early start of injection.

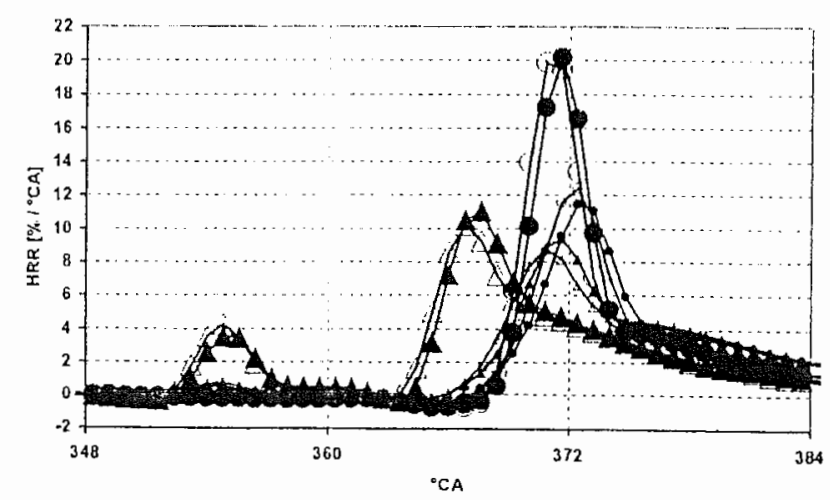

Figure 16: Heat release of the 8 experiments with late SOI.

No effects of pilot injection are visible in Figure 15 with low injection pressure. With high injection pressure the effect is clearly visible: The curves with $P I$ and high rail pressure show less fine particles $(>50 \mathrm{~nm})$ than those with the same rail pressure without $\mathrm{PI}$. The effect of pilot injection with early injection, is here opposite than it is with late injection, Figure 13. A reduced number of particles in the accumulation mode $(>50 \mathrm{~nm})$ and an important amount of nanoparticles $(<50 \mathrm{~nm})$ are detected in the experiments with high injection pressure. Size distributions with high injection pressure are bimodal, in the scanned range of particle size.

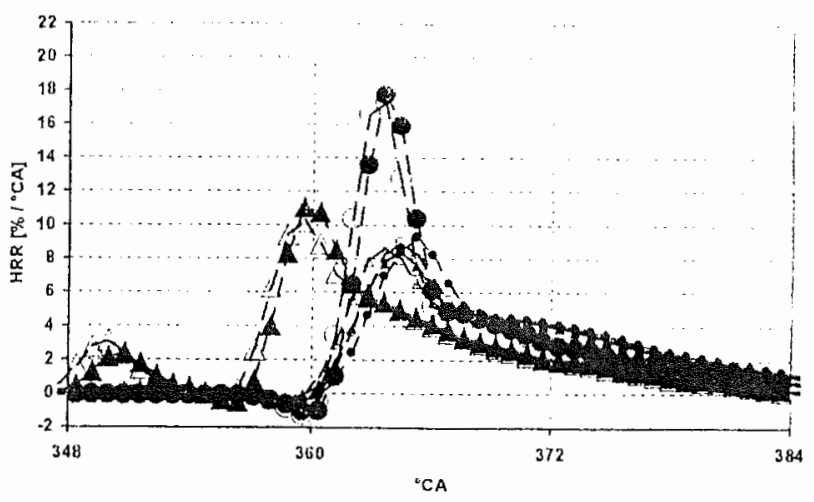

Figure 17: Heat release of the 8 experiments with middle SOI.

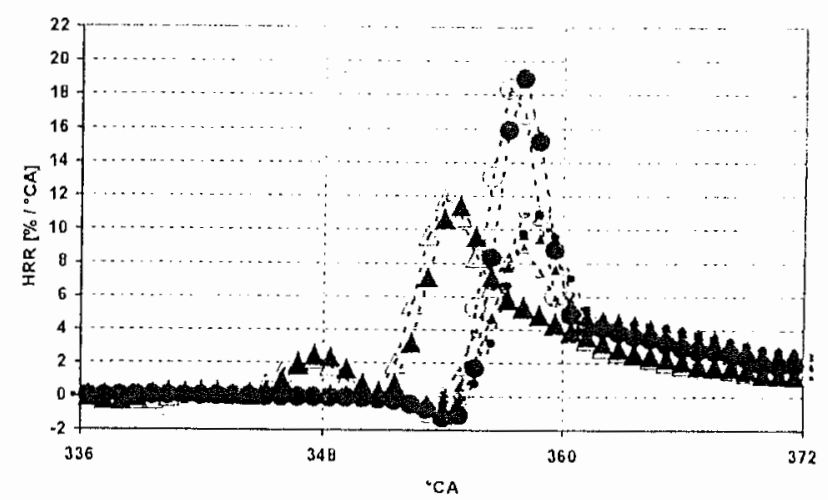

Figure 18: Heat release of the 8 experiments with early SOl.

In Figure 16 the heat release of the main combustion is advanced in the curves with high rail pressure and with $P$, relative to the other curves, although the start of injection for the main injection is equal in all eight experiments. In Figure $\mathbf{1 7}$ the first heat released after pilot injection (with high pressure) has not been equally shifted towards early, relative to figure 16 , as the remainder of these two curves. The time gap between pilot and main heat release (with high pressure) is shorter in Figure 18 then in Figures 16 and 17. With pilot injection at high pressure the time gap between the first and the second heat release is reduced, the more the start of injection is shifted towards early. The time gap between pilot and main injection pulses is equal in all performed experiments. This suggests that the mixing process of the pilot quantity has more time at disposal because the evaporation rate is slowed down, when the preparation of the pilot jet takes place farther away from TDC.

\section{SUMMARIZING EQUATIONS}

\section{Coefficients for Opacity}

The two summarizing equation for exhaust gas opacity that resulted from the two performed factorial 
experiments are presented in order to discuss the relation between injection timing and opacity.

In experiment middle-early-SOI the main combustion begins around TDC with 'Late Injection'. With 'Early Injection' it starts between -4 and $-10^{\circ} \mathrm{CA}$ (before TDC). Shifting start of injection towards early (Factor $D$ set) reduces opacity in the experiment for two reasons. First: The time at disposal of the fuel/air mixing process is increased (Because ignition delay is longer before TDC). Second: With earlier combustion, more time and higher temperatures are at disposal of the oxidation process of soot particles.

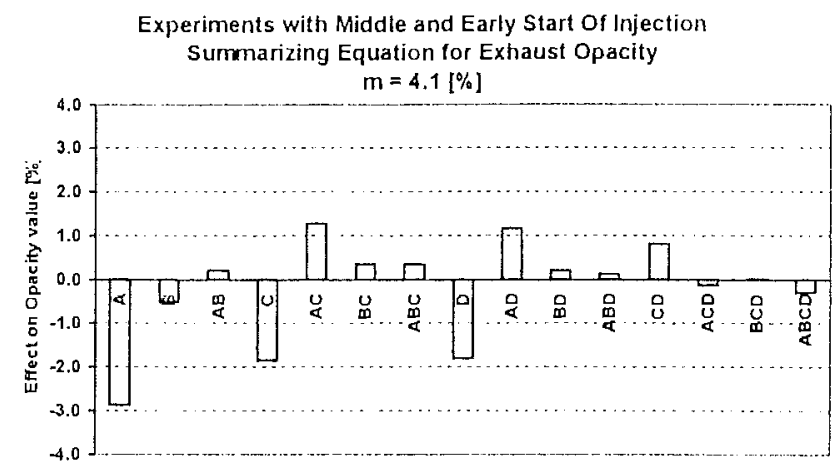

Figure 19: Coefficients for Opacity in experiment middle-early-SOI.

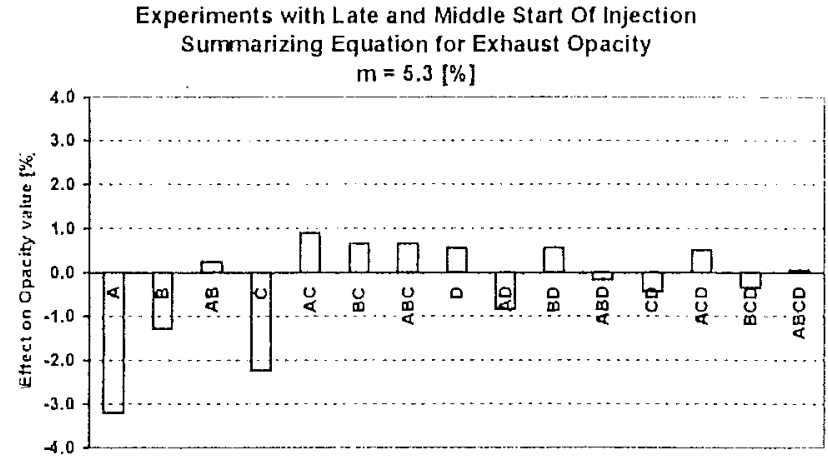

Figure 20: Coefficients for Opacity in experiment latemiddle-SOl.

In experiment late-middle-SOl the main combustion begins between +4 and $+10^{\circ} \mathrm{CA}$ (after TDC) with 'Late Injection'. With 'Early Injection' it starts around TDC. Shifting start of injection towards early (Factor $M$ set) increases slightly the opacity in this experiment. The two previously mentioned reasons act here in opposite direction: The time at disposal of the fuel/air mixing process is now reduced, because ignition delay is shorter around TDC. With earlier combustion, as in the previous experiment, more time and higher temperatures are at disposal of the oxidation process of soot particles

\section{Coefficients for Premixed Combustion Portion PCP}

The calculated PCP value depends mainly on the injection pressure and injection pattern (PI). It does not show the expected increase in premixed combustion portion with earlier injection in experiment middle-earlySOI (Figure 21). The variation of the start of injection has no effect on PCP values in experiment middle-earlySOl.

However the same factor ( $D=$ advancing $S O I$ ) reduces the portion of premixed combustion in experiment latemiddle-SOI (Figures 21 and 22). The PCP value reflects possibly an effect related to the movement of the piston during fuel injection and combustion. Before, around and after TDC the speed and direction of the movement change. The squish dictates the velocity difference between injected fuel and air charge. The radial vector components have opposite signs before and equal signs after TDC [3]. The flow field may thus influence the preparation of the mixture in two different senses in experiments middle-early-SOl and late-middle-SOI. The thermodynamic state of the charge is mainly a function of the piston position. Its influence is therefore equal in the two experiments.

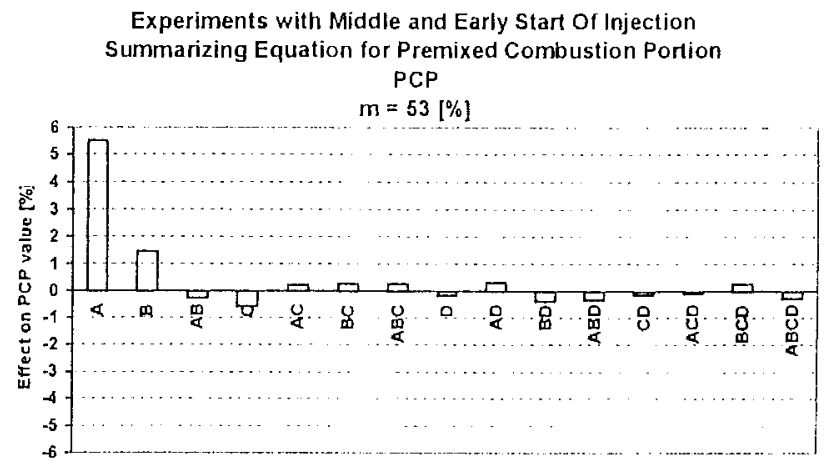

Figure 21: Coefficients for $P C P$ in experiment middleearly-SOI

Experiments with Late and Middle Start Of Injection Summarizing Equation for Premixed Combustion Portion PCP $m=56[\%]$

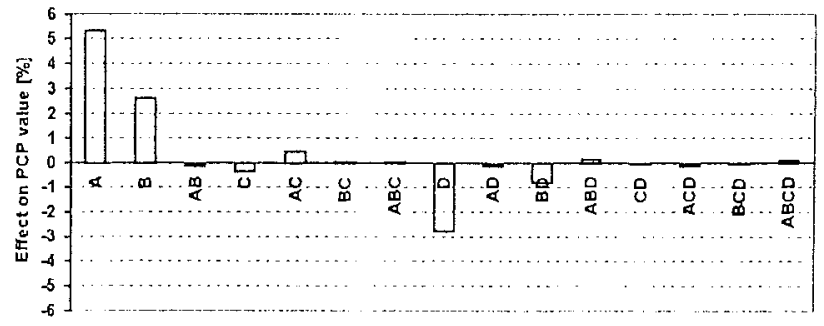

Figure 22: Coefficients for PCP in experiment latemiddle-SOI.

\section{CORRELATIONS BETWEEN NUMERICAL VALUES}

Results from measurements in all 24 tested engine operating conditions at 2 bar bmep, $2000 \mathrm{rpm}$ are presented in the following diagrams.

Relations with the Number of Particles per Volume Particulate Matter NPVP

Correlation between the PM mass collected on filters and the NPVP derived from SMPS measuring is 
observed in Figure 23. High NPVP values (finer particles) are associated with less PM mass emission. Two experiments make an exception: $A O C D$ and $A B C D$ are driven both with high injection pressure, low EGR, and SOl early before TDC

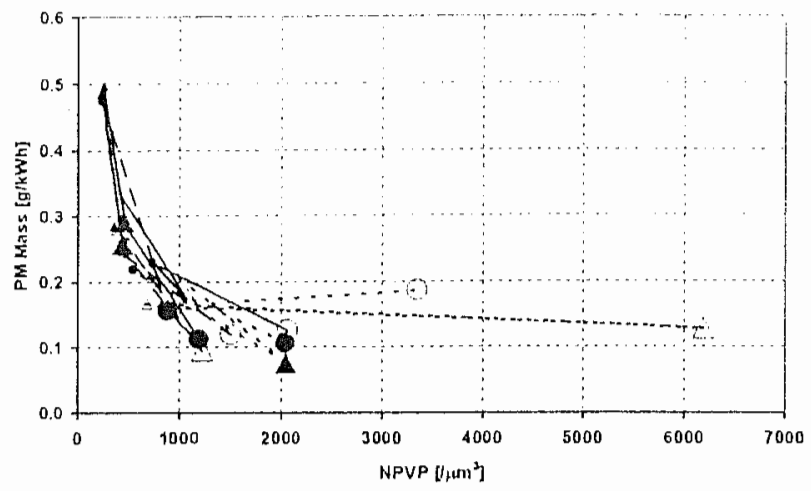

Figure 23: Mass of the particulate matter that was collected on filters during the 24 tested engine operating modes vs. the number of particles per volume particulate matter.

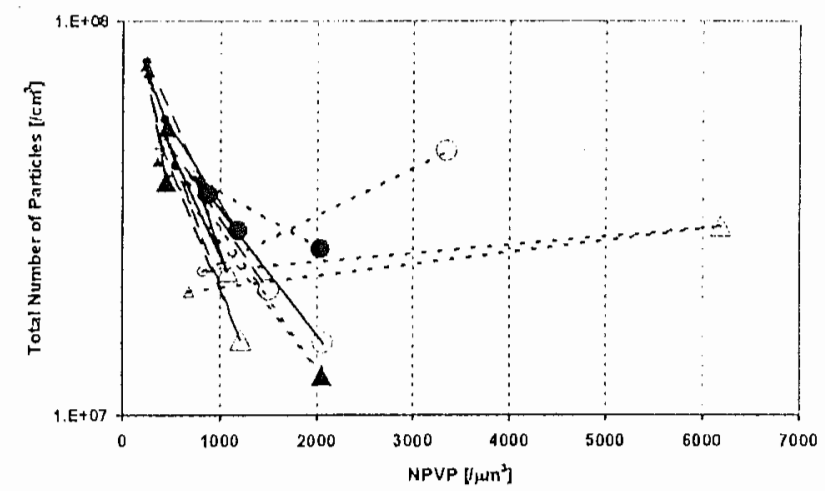

Figure 24: Total number of the particles (in the SMPS range of 16 to $630 \mathrm{~nm}$ ) sampled during the 24 tested engine operating modes vs. the number of particles per volume particulate matter.

Higher NPVP values (finer particles) are associated with reductions in the total number of particles (Figure 24). Experiments $A B C D, A O C D$ and $A B O D$ do not fit into the general trend of this diagram.

High NPVP values (finer particles) are associated with higher NOx emissions (Figure 25). Very high NOX emissions are observed in experiments $A B C D, A O C D$, $A B O D$ and $A O O D$

Correlation is observed in Figure 26 between the exhaust gas opacity and the NPVP derived from SMPS measuring in the range of 16 to $630 \mathrm{~nm}$. High NPVP values (finer particles) are associated with less opacity. The exceptions of $A O C D$ and $A B C D$ are visible, though their opacity values are very low and near the limit of detection.

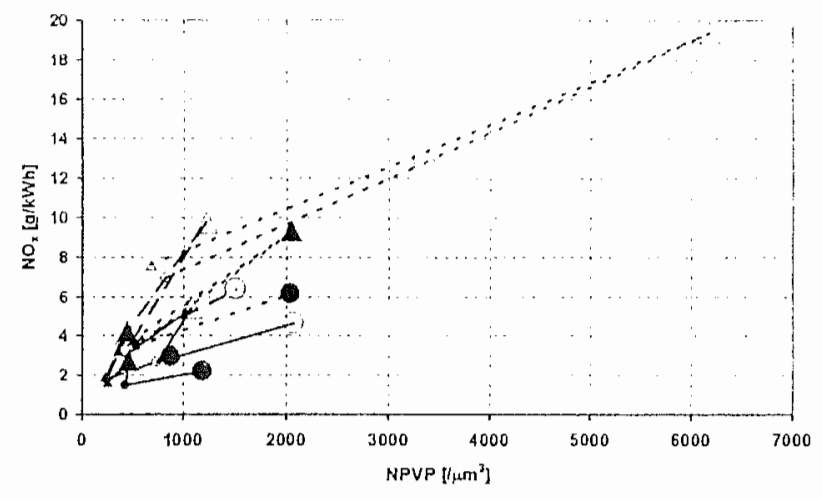

Figure 25: NOx emissions registered during the 24 tested engine operating modes vs. the number of particles per volume particulate matter.

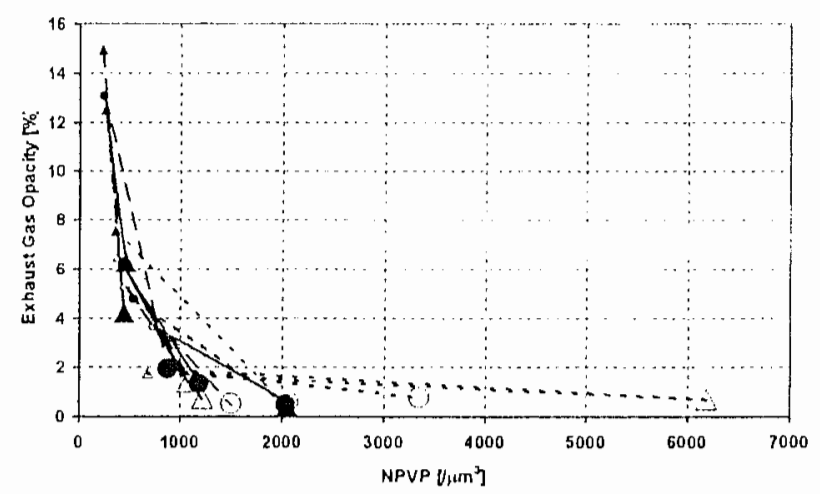

Figure 26: Exhaust gas Opacity readings registered during the 24 tested engine operating modes vs. the number of particles per volume particulate matter.

\section{Relations with the Premixed Combustion Portion PCP}

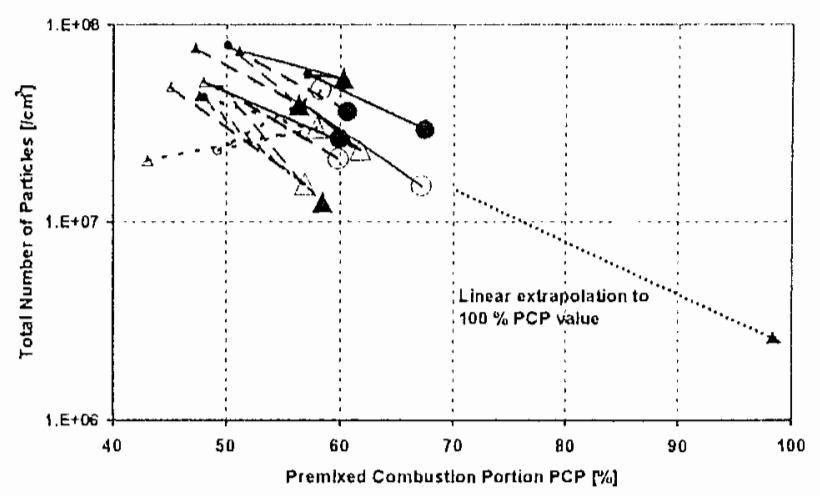

Figure 27: Total number of the particles (in the SMPS range of 16 to $630 \mathrm{~nm}$ ) sampled during the 24 tested engine operating modes vs. the premixed combustion portion (PCP values) that resulted from heat release analysis

High premixed combustion portion yields less particles, for a given start of injection. Increasing the rail pressure reduces the total number of particles, as long as the SOI is not (too) early before TDC. Extrapolation of this trend to $100 \% \mathrm{PCP}$ yields a number concentration in the order of $10^{6}$ particles per $\mathrm{cm}^{3}$ (Figure 27). 
In Figure 28 correlation between PCP and NPVP is observed. The experiments $A B C D, A O C D, A B O D$ and $A \cup O D$ are visible as exceptions to the trend of the other experiments.

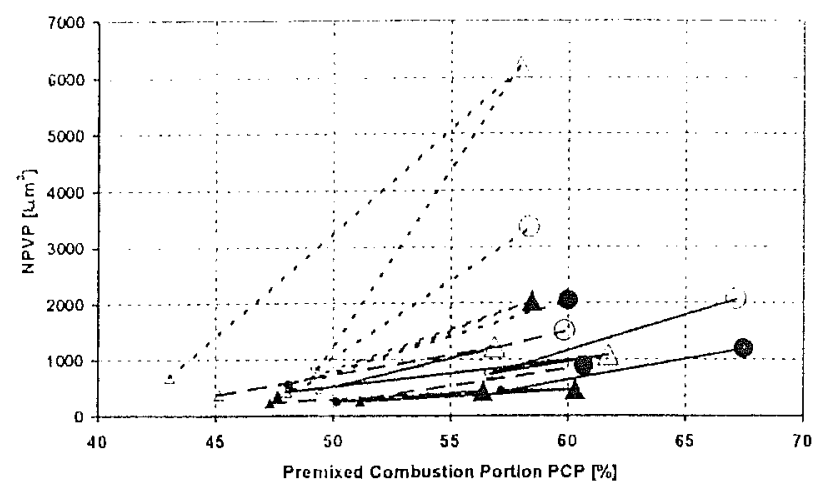

Figure 28: Number of particles per volume particulate matter (NPVP for the SMPS range of 16 to $630 \mathrm{~nm}$ ) calculated for the 24 tested engine operating modes vs. the premixed combustion portion (PCP values) that resulted from heat release analysis.

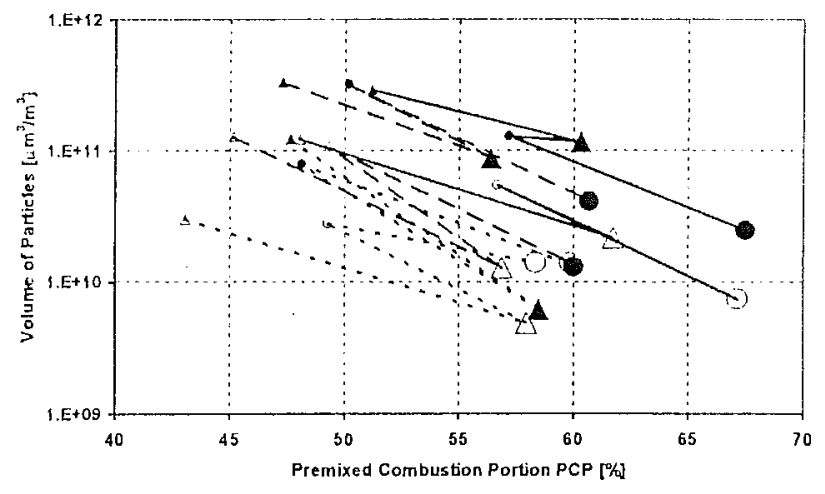

Figure 29: Calculated volume of the particles (in the SMPS range of 16 to $630 \mathrm{~nm}$ ) for the 24 tested engine operating modes vs. the premixed combustion portion (PCP values) that resulted from heat release analysis.

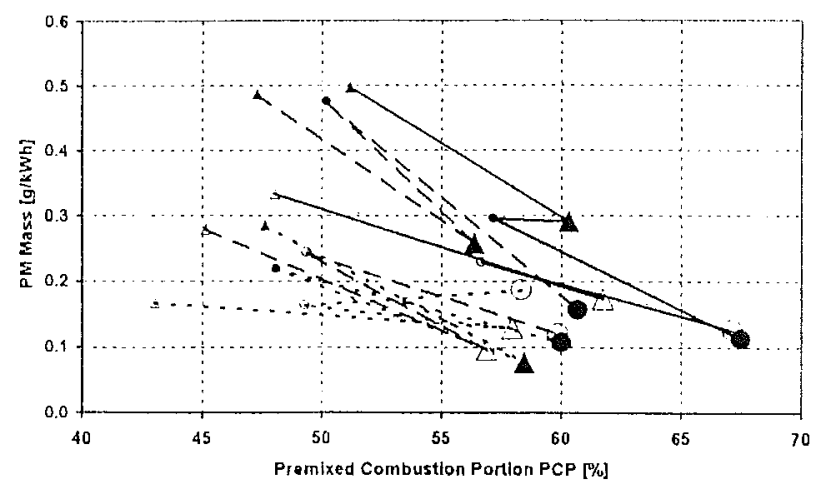

Figure 30: Mass of the particulate matter collected on filters during the 24 tested engine operating modes vs. the premixed combustion portion (PCP values) that resulted from heat release analysis.

Correlation between PCP and the volume of the sampled particles depends on the start of injection. With late and middle SOI less volume of particles is emitted with less EGR (Figure 29). The volume is calculated from the number of particles under the assumption that all the particles are spheres with diameter equal to their electric mobility diameter.

Correlation between the calculated premixed combustion portion (PCP) and the particulate matter collected on filters is shown in Figure 30. The extent of the agreement depends on the timing of the injection. The influence on PM emissions by the factors SOI and EGRrate decreases with increasing premixed combustion portion PCP.

\section{DISCUSSION}

The high values of premixed combustion portion have been realized in this work by simple means at the price of excessively high $\mathrm{NO}_{x}$ emissions and peak cylinder pressure.

Similar values for the premixed combustion portion and almost identical particle size distributions can be realized with different combinations of parameters like injection pressure (varied from 400 to 1200 bar), injection pattern and injection timing.

The presented summarizing equations for exhaust gas opacity show that, at the tested operating mode of 2 bar bmep and $2000 \mathrm{rpm}$, advancing the start of injection does not necessarily result in reduced engine exhaust gas opacity. This suggests that the PM emissions of a small $\mathrm{Cl}$ engine at part load do not depend mainly on the time that is available for the oxidation of soot particles.

The results presented in Figures 27 to 30 confirm the advanced hypothesis to an extent: The numbers of emitted particles as well as their mass can be effectively reduced, without changing the start of injection, by increasing that part of the fuel that reacts in a premixed combustion. This consideration applies to a small, highspeed $\mathrm{Cl}$ engine run at part load on diesel fuel

This observed reduction in total number of particles is achieved by reducing the number of particles with electric mobility diameter larger than $50 \mathrm{~nm}$. This results in an increase in NPVP values (finer particles on an average) also in the cases where no important increase in the number of the smallest particles is seen.

Exceptions have however been observed. Large numbers of nanoparticles ( $<50 \mathrm{~nm}$ ) have been counted in four operating points that influence the results of experiment middle-early-SOI: ABCD, $A O C D$ and to a minor extent $A B O D$ and $A O O D$ do not fit well the trendlines of Figure 23-24. These exceptions are visible also in Figure 26-28. Combustion occurs earlier in these four experiments, than in the remainder twelve (Figure 18). They also show high NOx emissions (Figure 25, this effect is masked for the two experiments with high EGR rate).

Two different hypothesis are noted here in order to explain these exceptions.

- The time and temperature histories of the burnt mixture, differ in these four experiments from those in the remaining operating conditions. With more time spent at higher temperatures an improved but 
still incomplete oxidation process of previously created soot could be responsible for the emission of a significant number of small particles.

- The concentration of fine solid carbon particles in the agglomeration mode (> $50 \mathrm{~nm}$ ) is lower in these four experiments than in the remaining ones: A higher number of nanoparticles $(<50 \mathrm{~nm})$ is formed by homogeneous nucleation of volatile particle precursors during the dilution of the exhaust gas [5].

Some of the presented particle size distributions seem to suggest the existence of a particle mode with electric mobility diameters much smaller than $50 \mathrm{~nm}$. An investigation is under way, with focus on the nanoparticles, and the chemical analysis of the particulate matter collected on filters. The influence of the measuring techniques on the results of the investigation is thereby given further attention.

\section{CONCLUSION}

- With higher premixed combustion portion (PCP values) a significant reduction in the number of the detected particles is achieved. This occurs with late and middle start of injection mainly by reducing the number of fine particles $(>50 \mathrm{~nm})$, without increase in the number of nanoparticles $(<50 \mathrm{~nm})$.

- With higher premixed combustion portion a significant reduction in averaged size (higher NPVP values) of the detected particles is achieved This occurs with late and standard injection mainly by reducing the number of fine particles $(>50 \mathrm{~nm}$ ), without increase in the number of nanoparticles $(<50$ $\mathrm{nm})$.

- Only the averaged size, but not the number of the detected particles is reduced with very early heat release. Further work on the composition of the detected particles is under way to complement and interpret this observation.

- The calculated volume of the detected particles and the measured mass of the emitted particulate matter are reduced when the relative importance of diffusion controlled combustion is decreased.

- The relative importance of premixed combustion as part of the total heat release is a primary factor influencing PM emissions of fast running $\mathrm{Cl}$ engines operated at part load.

- Extrapolation of the results of this work to a compression-ignition engine with $100 \%$ premixed combustion suggests, that low particle number concentrations similar to those of spark ignition engines could be realized in an appropriately designed compression-ignition engine.

\section{ACKNOWLEDGMENTS}

This work has been made possible by the Research Foundation of the Swiss Petroleum Industry FEV, Zürich with ongoing and important financial support. It is a cooperation of LVV ETH, Zürich and EMPA, Dübendorf.
For hardware and further support we are endebited to GM R\&D Center Diesel Section and to the engine manufacturer. The authors would like to gratefully express their appreciation to all the involved persons.

e-mail:jaeger@/vv.iet.mavt.ethz.ch

\section{REFERENCES}

1. Obrecht, P.: 'WEG Rechenprogramm zur Berechnung des Wärmeentwicklungsgesetzes', 5603 Staufen, 1995/99.

2. Heywood, J. B.: 'Internal Combustion Engine Fundamentals', 1988 McGraw-Hill

3. Kittelson, D. B.: 'Engines and nanoparicles: a review', 1998 Journal of Aerosol Science Vol.29 number 5/6

4. Prescher, K., Astachow, A., Krüger, G., Hintze, K.: 'Investigation of the atomization and Evaporation of Diesel and Heavy Fuel Sprays using Optical Measurement Techniques', SAE 1999-01-0520

5. Kittelson, D. B., Imad Abdul-Khalek.: Nanoparticle Formation during Exhaust Dilution', $2^{\text {nd }}$ ETH Workshop on Nanoparticle Measurement, Zürich, 1998

6. Hall, D.E., Heinze, P. et al.: 'a study of the number, size \& mass of exhaust particles emitted from european diesel and gasoline vehicles under steady-state and european driving cycle conditions', CONCAWE, Brussels, 1998

\section{DEFINITIONS, ACRONYMS, ABBREVIATIONS}

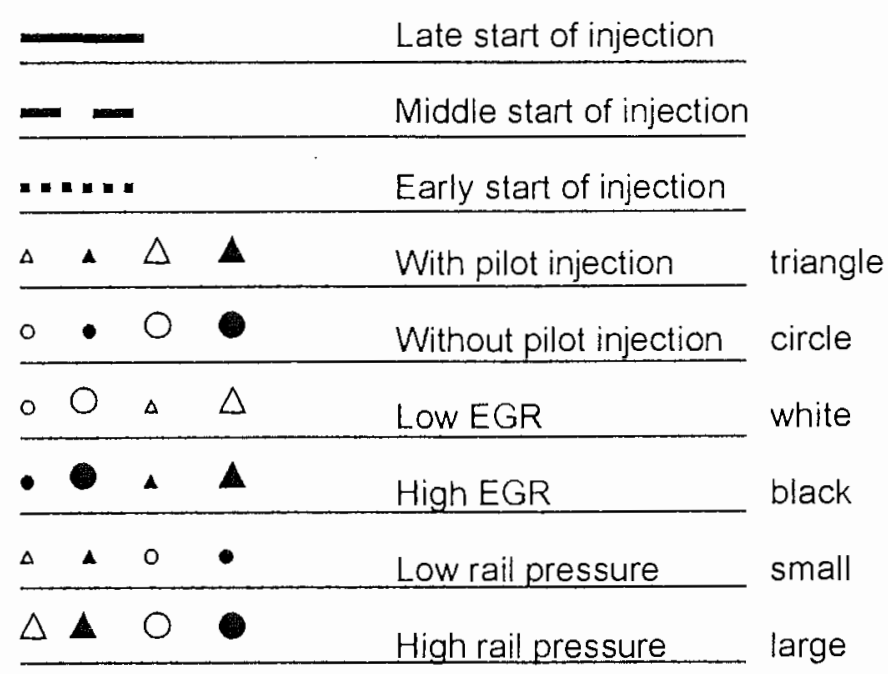

Nanoparticles

particles with electric mobility diameter $<50 \mathrm{~nm}$. Fine Particles

particles with electric mobility diameter $>50 \mathrm{~nm}$.

Coarse Particles

particles with electric mobility diameter $>1000 \mathrm{~nm}$ $\mathrm{Cl}$

compression-ignition

CR

common-rail

DI

direct-injection

EGR

exhaust gas recirculation [mass \%]

HRR

heat release rate $\left[\% /{ }^{\circ} \mathrm{CA}\right]$

IHR

integrated heat release [\%]

PCP 
premixed combustion portion [\% of IHR] PI

pilot injection

PM

particulate matter

SMPS

scanning mobility particle sizer
SOI

start of injection

TDC

top dead center

$\lambda$

air/fuel ratio [-] 